\title{
Traditional market-animal projects positively influence 4-H enrollment
}

\author{
Linear modeling techniques suggest that beef, sheep and swine projects all contribute to increased \\ county 4-H enrollment, though the degree of increase varies.
}

by Josh Davy, Larry Forero, Nathaniel W. Caeton, Ashton Hubbard and Allison Gross

Online: https://doi.org/10.3733/ca.2020a0008

\section{Abstract}

The 4-H Youth Development Program (4-H) teaches life skills. An understanding of the factors that drive participation in the California 4-H program can help the organization target its efforts to increase enrollment and benefit more California youth as they move toward adulthood. 4-H has long been associated with market-animal projects, but the effect of these projects on enrollment is not known. In this study, 7 years' worth of enrollment data from 27 Northern California counties was evaluated with linear modeling techniques to determine the impact of market-animal projects (beef, sheep and swine) on program participation. The analysis demonstrated that market-animal projects produce significant, positive effects on enrollment. Each beef project contributed nearly four new members to county enrollment; a single sheep project yielded just over two new members; and two new swine projects produced a single new enrollment. Region and population density influenced membership but year within the study period did not. These results demonstrate the multiplicative effect of beef and sheep projects on county 4-H enrollment.

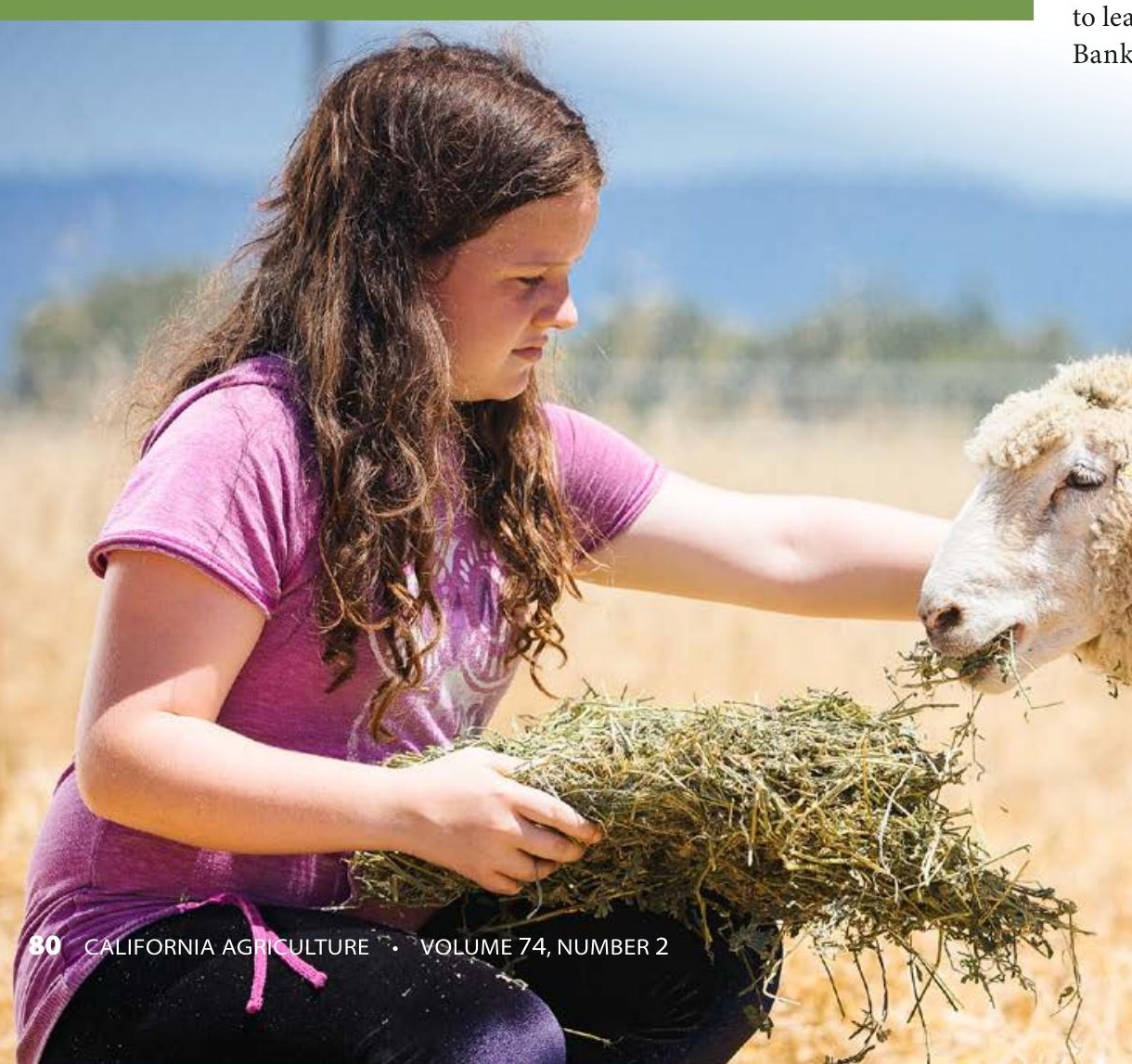

he positive impact on youth development of the
4-H Youth Development Program (4-H) is well
documented (Ladewig and Thomas 1987). Participation in the program can help discourage risky and unhealthy behavior (Jelicic et al. 2007; Schwartz et al. 2010). Alumni of the program have indicated that $4-\mathrm{H}$ positively affected their leadership and communication skills and made them more responsible (Radhakrishna and Doamekpor 2009). Published research indicates that, in Shasta and Trinity counties, more than $90 \%$ of members developed the life skills of sharing, communicating, planning and organizing, goal-setting, keeping records, taking responsibility and self-motivation (Forero et al. 2009). Research suggests that the program can lead young people to maintain a positive image of agriculture (Croom and Flowers 2001) and can influence their college enrollment decisions (Rayfield et al. 2013; Torres and Wildman 2001). Once program alumni begin college, the civic and leadership skills they gained in the program can transfer to leadership roles in college (Park and Dyer 2005) - and, later, to leadership roles in their adult careers (Cano and Bankston 1992; Hoover et al. 2007).
According to the researchers, traditional 4-H livestock projects play a critical role in encouraging youth to participate in the $4-\mathrm{H}$ Youth Development Program. 
Some research hints that member interest in animals could be linked to increased 4-H enrollment (Esters and Bowen 2004) and that skills learned in market-animal projects help youth both at school and at home as they become more dependable and confident (Rusk et al. 2003). Additionally, 4-H alumni have indicated that involvement in livestock projects had a positive impact on the development of life skills (Ward 1996).

Though animal projects are highly visible and beneficial, it is not clear how such projects influence enrollment. Attempts to understand such dynamics can prove confounding because enrollment can potentially be affected by factors like fluctuations in the number of eligible youth, local population density or the geographic regions where youth reside.

Because animal projects are among the most recognized components of $4-\mathrm{H}$, this study examined the importance of beef, sheep and swine projects in relation to total $4-\mathrm{H}$ enrollment. Previous research into 4-H recruitment and retention has drawn on survey information to produce data that describes drivers of 4-H interest - or, specifically, describes what participants like or dislike about the program (Gliem and Gliem 2000; Wingenbach et al. 1999). Much of this work, however, produces subjective results that, instead of contributing to enrollment and retention, prepare program managers to deliver the program in meeting settings.

While improving program delivery is important, the main hypothesis presented here is that encouraging market-animal projects in Northern California could increase overall 4-H enrollment at greater than a 1:1 rate (i.e., adding one market-animal project could increase enrollment by more than one youth participant). This research accounts for variables, beyond marketanimal projects, that might reasonably be thought to influence total enrollment. These variables include year, region and population density. Taking these variables into account, a secondary hypothesis is that total enrollment varies naturally from year to year (trends in time), that differences in location (space) influence total enrollment and that population density (people per square mile) affects the pool of potential members and resulting enrollment. The secondary hypothesis seems very practical - but since this type of modeling has not previously been conducted with $4-\mathrm{H}$ enrollment data, no known research-based reference can prove its validity.

County enrollment data over 7 years was used to determine how participation in beef, swine and sheep projects affected enrollment in Northern California. This was accomplished with a six-factor (with interactions) general linear model that included the three livestock species, year, region and population density to determine if, for each factor, a significant causal relationship with total enrollment existed. The novelty of this approach is that it allows the influences of all the factors to be simultaneously considered, resulting in a specific interpretation of each individual factor's contribution to enrollment, independent of the contributions of the others. Because of this, the model can determine how many new 4-H memberships are produced by a new market-animal project — regardless of year, location or population density.

\section{Methods}

\section{Animal project data collection}

This research focused on 27 Northern California counties - rural, suburban and urban. The 27 counties display considerable diversity in population and geography and together they constitute a sample of ample size for investigating the importance of marketanimal projects in 4-H enrollment. Data from the 4-H Online enrollment system was accessed to determine each county's annual level of participation in species-specific livestock projects and its total annual enrollment.

The 4-H program's oldest mode of delivery is the community club, an organized group of at

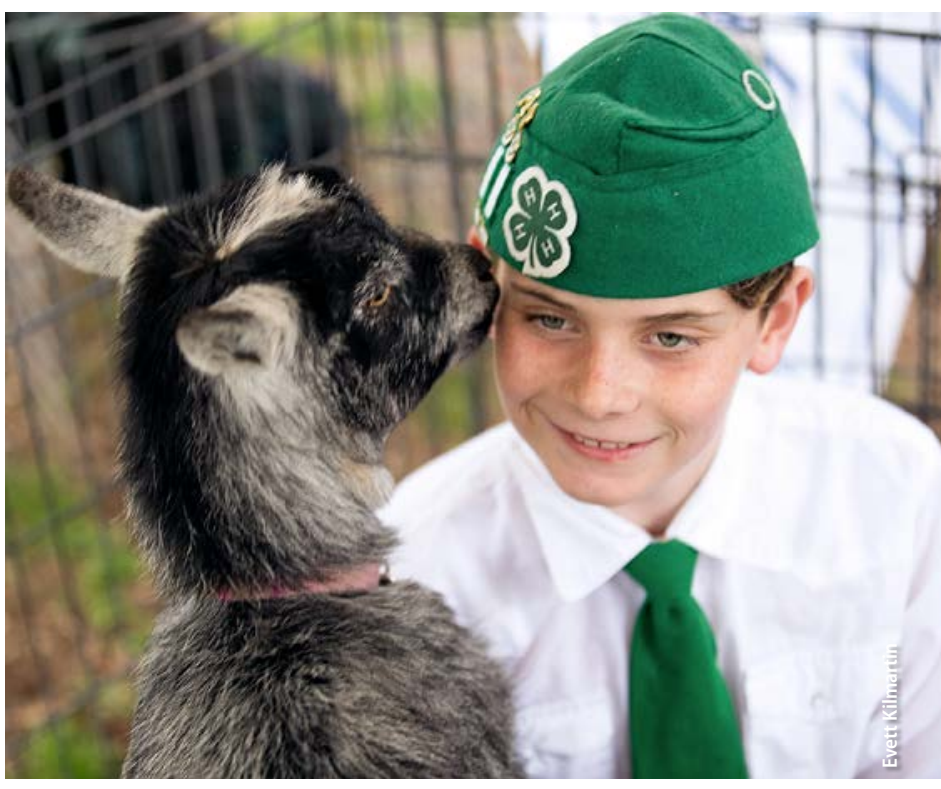
least five young people drawn from at least three different families and led by at least two adult volunteers. Potential members who wish to join the community club program choose a club at the time they enroll in $4-\mathrm{H}$. They typically choose a club located in the area where they reside. Once they have enrolled, they choose to participate in one or more projects - such as livestock, archery or photography - that the club offers. Members are free to participate in as many projects as they like, but they must choose to participate in at least one. Members are required to attend both community club meetings and project meetings. Typically, projects facilitate in-depth learning about a particular subject while community club meetings provide opportunities for leadership and community service. Extension staff, using 4-H Online, collect and retain county data about projects and use it to prepare an annual, federally required report known as an ES-237 Activity Count.

In this research, when data derived from $4-\mathrm{H}$ Online was used to determine the number of speciesspecific livestock projects conducted in each county, noncategorized projects (e.g., "sheep") and categorized projects (e.g., "market sheep") were - to account for categorization errors that may have occurred when individual families enrolled in $4-\mathrm{H}$ at the local level
To determine how participation in beef, swine and sheep projects affected 4-H enrollment in Northern California, the authors used a six-factor general linear model that included the three livestock species, year, region and population. 
- both included in the totals. The same approach was taken for each of the three livestock categories. Duplicate records were removed from the gross total membership reported for each year to arrive at the net totals. To make the research as current as possible, while still covering a period long enough to allow for accurate identification of trends, data was collected over an annual enrollment period of 7 years, from 2008 to 2015 .

\section{Region}

In an effort to limit degrees of freedom in the model's categorical variables, counties were categorized as belonging to five distinct Northern California regions (fig. 1), which were coded as one through five. The regions are: (1) northern coastal counties, (2) northern mountain counties, (3) northern valley counties, (4) southern valley and coastal counties and (5) southeastern foothill/mountain counties.

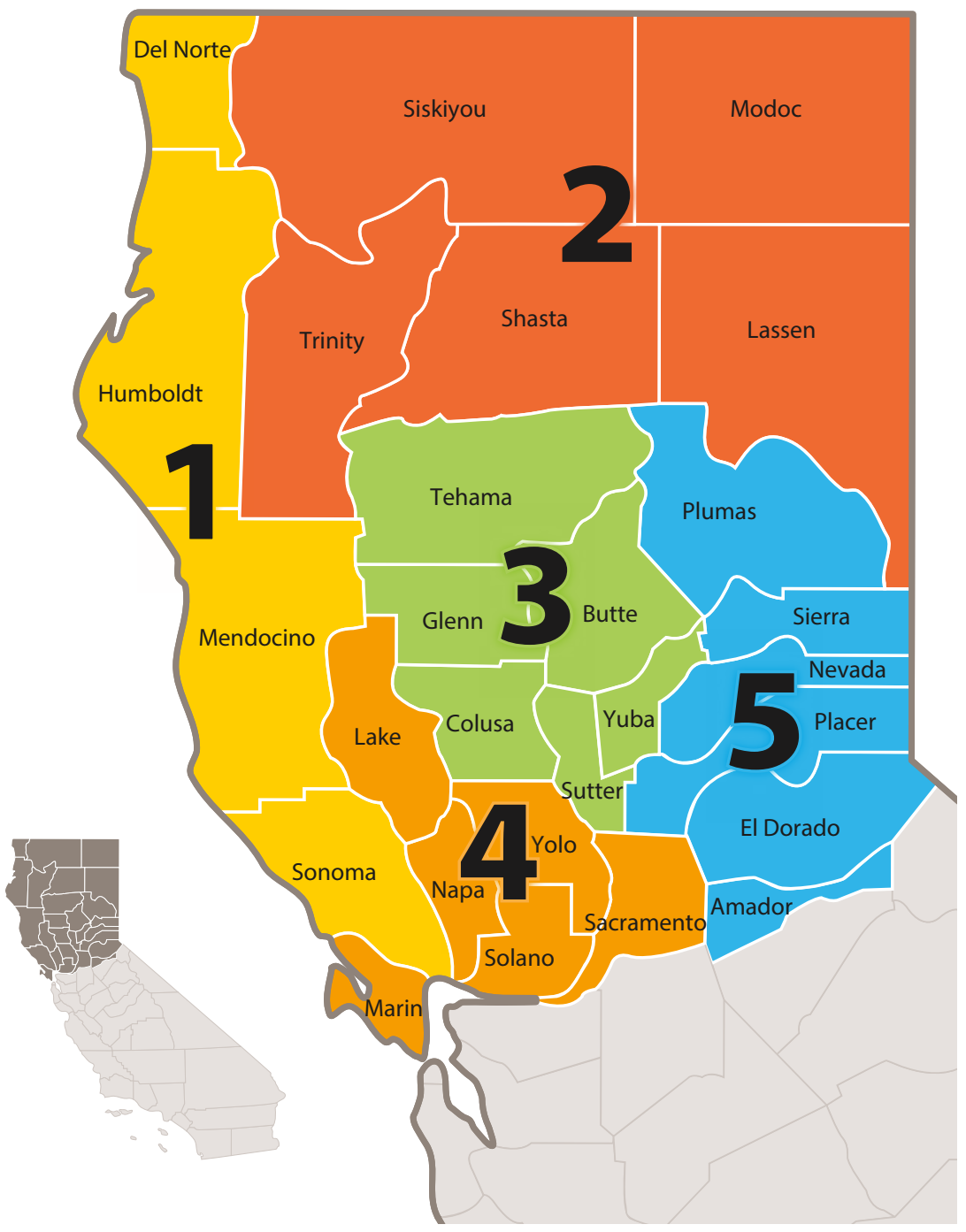

FIG. 1. Geographical regions coded from 1 to 5 .

\section{Density}

Information from the U.S. Census Bureau (USCB 2010) was used to determine each county's population per square mile, or population density. All Census Bureau data on population and population density were collected from the 2010 census. Population per square mile by county is outlined in table 1 .

\section{Statistical analysis}

To test the potential impact of multiple variables on 4-H enrollment, a GLM Type III sums-of-squares procedure was used in Statgraphics (Statpoint Technologies 2009). Quantitative variables included population density and enrollments in swine, sheep and cattle projects. Categorical variables included year (time) and region (space). Initially, all two-way interactions were included. However, it was found that including interactions caused multicollinearity, which can increase the amount of error in estimation and lessen reliability in inferences about data. All interactions were therefore removed from the model. Insignificant variables $(P>0.05)$ were eliminated from the final model. Estimates of

TABLE 1. Population density per square mile by county

\begin{tabular}{|c|c|}
\hline $\begin{array}{l}\text { Population density per } \\
\text { square mile }\end{array}$ & County \\
\hline 2.5 & Modoc \\
\hline 3.4 & Sierra \\
\hline 4.3 & Trinity \\
\hline 7.2 & Siskiyou \\
\hline 7.7 & Lassen \\
\hline 7.8 & Plumas \\
\hline 18.6 & Colusa \\
\hline 21.4 & Glenn \\
\hline 21.5 & Tehama \\
\hline 25.1 & Mendocino \\
\hline 28.4 & Del Norte \\
\hline 37.7 & Humboldt \\
\hline 46.9 & Shasta \\
\hline 51.5 & Lake \\
\hline 64.1 & Amador \\
\hline 103.1 & Nevada \\
\hline 106.0 & El Dorado \\
\hline 114.2 & Yuba \\
\hline 134.4 & Butte \\
\hline 157.3 & Sutter \\
\hline 182.4 & Napa \\
\hline 197.9 & Yolo \\
\hline 247.6 & Placer \\
\hline 307.1 & Sonoma \\
\hline 485.1 & Marin \\
\hline 503.0 & Solano \\
\hline $1,470.8$ & Sacramento \\
\hline
\end{tabular}


enrollments per variable and standard errors were calculated on all significant quantitative variables. Least square mean figures were developed using Fisher's least significant difference test. An analysis of variance was used to examine the significance of density and region on individual livestock species projects and the influence of density on the ratio of total market projects to enrollment. Pearson product correlations were run between density and all three livestock projects.

\section{Results}

The overall model explained $84 \%$ of the variance in total enrollment $(R=84)$. Multiple variables were found to contribute to total $4-\mathrm{H}$ enrollment. Swine $(P<0.01$, estimate 0.62 , standard error [SE] 0.21$)$, sheep $(P<0.01$, estimate 2.30 , SE 0.30$)$, cattle $(P<0.01$, estimate 3.97 , SE 0.67$)$, density $(P<0.01$, estimate 0.19 , SE 0.03$)$ and region $(P<0.01)$ (fig. 2$)$ all significantly influenced enrollment (table 2). Year $(P=0.91)$ was not significant, indicating limited annual variation in total enrollment across the study period; year was thus eliminated from the final model. The resulting final model to predict enrollment, with density, region, sheep, swine and beef as variables, is presented as:

total enrollment $=92.3077-41.8653 \times 11(1)-$

$132.343 \times 11(2)-54.8407 \times 11(3)+144.675 \times$

$11(4)+3.97672 \times$ market beef cattle $+2.29524 \times$ market sheep $+0.618433 \times$ market swine $+0.185265 \times$ density per square mile

where

$$
\begin{aligned}
& \begin{array}{l}
I 1(1)=1 \text { if region code }=1,-1 \text { if region code }=5, \\
0 \text { otherwise }
\end{array} \\
& \begin{array}{r}
11(2)=1 \text { if region code }=2,-1 \text { if region code }=5, \\
0 \text { otherwise }
\end{array} \\
& I 1(3)=1 \text { if region code }=3,-1 \text { if region code }=5, \\
& 0 \text { otherwise } \\
& I 1(4)=1 \text { if region code }=4,-1 \text { if region code }=5, \\
& 0 \text { otherwise }
\end{aligned}
$$

\section{Discussion}

4-H market-animal projects are a highly visible component of the 4-H program. This analysis identified how multiple variables independently influence enrollment. These data indicate that traditional 4-H livestock projects play a critical role in encouraging youth to participate in the 4-H Youth Development Program.

This analysis indicates that the variables tested have a statistically significant relationship. The influence of these specific livestock market projects on 4-H enrollment can be inferred from the mechanics of program participation. Projects are the basis of the delivery method for traditional 4-H community clubs. Each
640

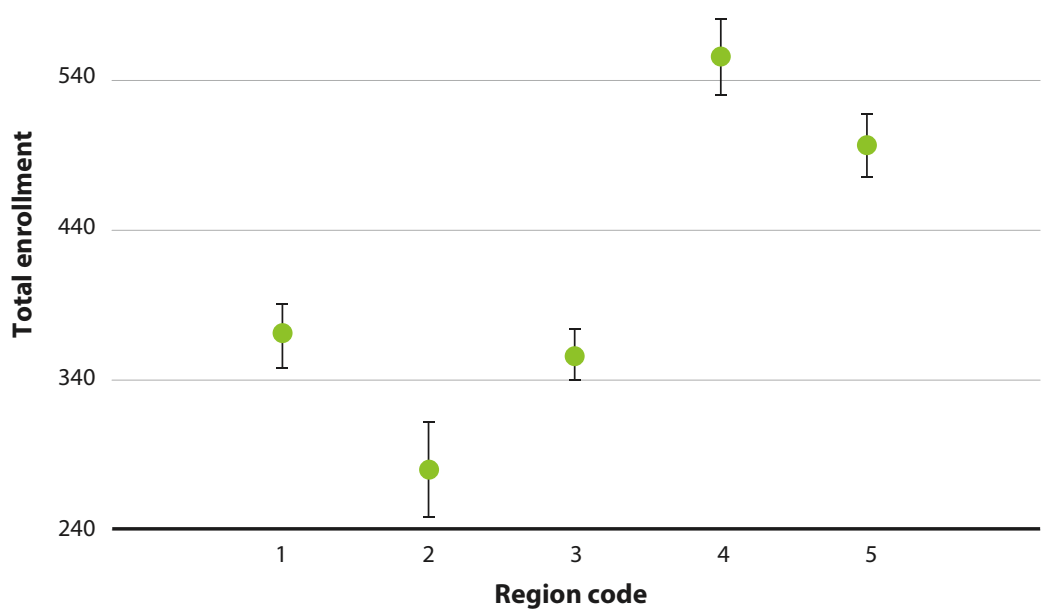

FIG. 2. Least square means of total enrollment per county by region in (1) northern coastal counties, (2) northern mountain counties, (3) northern valley counties, (4) southern valley and coastal counties and (5) southeastern foothill/mountain counties.

member is required to choose at least one project upon enrollment - it is not possible to complete the enrollment process without choosing a project. Youth are free to choose any project that interests them and may choose more than one project. They are not required to choose market-animal projects. New or returning members choose specific project(s), and those project(s) drive enrollment. The authors speculate that a member enrolling in $4-\mathrm{H}$ creates awareness among siblings, peers and friends about the opportunities that 4 -H offers. For example, if a youth is interested in raising a market animal, the youth's parTABLE 2. Estimated influence of the occurrence of a single additional market-animal project on total $4-\mathrm{H}$ enrollment, along with standard error

\begin{tabular}{|l|c|c|}
\hline Parameter & $\begin{array}{c}\text { Estimated increase in } \\
\text { enrollment for each } \\
\text { market project }\end{array}$ & $\begin{array}{c}\text { Standard } \\
\text { error }\end{array}$ \\
\hline $\begin{array}{l}\text { Market beef } \\
\text { cattle }\end{array}$ & 3.98 & 0.67 \\
\hline Market sheep & 2.3 & 0.3 \\
\hline Market swine & 0.62 & 0.21 \\
\hline Density & 0.19 & 0.03 \\
\hline
\end{tabular}
ents may reason that, since they will be taking one child to community club meetings, they might as well involve siblings as well because 4-H might offer projects that appeal to them. Determining the drivers that influence familial participation in the program is beyond the scope of this paper but should be explored.

The model indicates that the primary hypothesis of this research - that swine, beef and sheep projects are important to $4-\mathrm{H}$ enrollment - is true. The three animal types, however, are important at different levels. The model shows that nearly two swine projects were required to encourage an additional enrollment in $4-\mathrm{H}$ (beyond the two enrollments associated with the swine projects themselves). A single sheep project increased enrollment by just over two members and a beef project resulted in an increase of close to four members (table 2). The significance of these estimates is that, due 
than region 5 (fig. 2). Since density was accounted for separately, urban versus rural demographics are not likely the cause of the higher enrollment in these two regions. 4-H educators would benefit if the reasons for higher enrollment in these two regions were explored. Perhaps study of these regions could lead to development of programmatic practices that would benefit other regions.

Region also appeared to be more pronounced in its effect on livestock projects than did density (table 3). Specific regions differed in the number and types of livestock projects. It is difficult to determine the cause of these differences. They could be cultural in nature or due to mimicry of local agriculture in the area.

Although multiple variables affect subsequent $4-\mathrm{H}$ enrollment, traditional market-animal projects are considered a significant avenue for encouraging youth to join an organization that offers many additional benefits, including leadership training and self-responsibility. Rusk et al. (2003) have discussed the positive lessons gained from animal science projects.

The results of this research show that marketanimal projects positively increase enrollment; through participation in these projects, youth are exposed to the other constructive aspects of the youth development program. Future research might usefully focus on barriers that prevent youth participation in marketanimal projects. Overcoming these barriers could result in an increase in participation in the 4-H Youth Development Program. Lessons learned from marketanimal projects, coupled with the structure of the traditional community club system, produce encouraging outcomes well documented among 4-H alumni. CA
J. Davy is UC Cooperative Extension (UCCE) Livestock and Natural Resources Advisor in Tehama, Glenn and Colusa counties, and County Director for Tehama County; L. Forero is UCCE Livestock and Natural Resources Advisor in Shasta and Trinity counties, and County Director for Shasta County; N.W. Caeton is UCCE Youth Development Advisor in Shasta, Tehama and Trinity counties; A. Hubbard is UCCE Community Education Specialist in Tehama County; and A. Gross is UCCE Community Education Specialist in Tehama County.

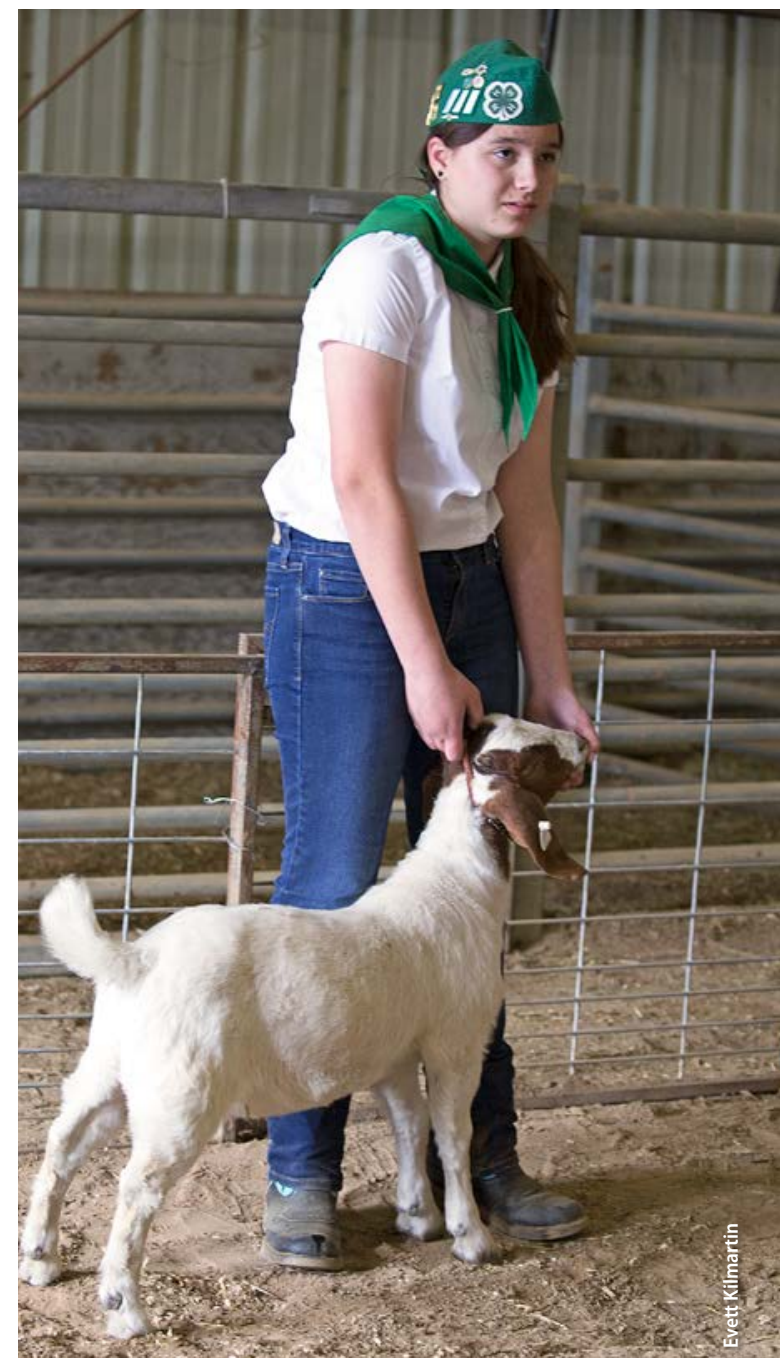

\section{References}

Cano J, Bankston J. 1992. Factors which influence participation and non-participation of ethnic minority youth in Ohio 4-H programs. J Agr Education 33(1):23-9.

Croom DB, Flowers JL. 2001. Factors influencing an agricultural education student's perception of the FFA organization. J Agr Education 42(2):2837.

Esters LT, Bowen BE. 2004. Factors influencing enrollment in an urban agricultural education program. J of Career and Technical Education 21(1):25-37.

Forero L, Heck K, Weliver P, et al. 2009. Member record books are useful tools for evaluating 4-H club programs. Calif Agr 63(4):215-9. http://calag. ucanr.edu/archive/?article=ca. v063n04p215
Gliem RR, Gliem JA. 2000. Factors that encouraged, discouraged, and would encourage students in secondary agricultural education programs to join the FFA. In: Proc 27th Ann Nat Agric Educ Res Conf, San Diego, CA. p 251-63.

Hoover TS, Scholl JF, Dunigan AH, Mamontova N. 2007. A historical review of leadership development in the FFA and $4-\mathrm{H}$. J Agr Education 48(3):100-10.

Jelicic H, Bobek DL, Phelps

$E$, et al. 2007. Using positive youth development to predict contribution and risk behaviors in early adolescence: Findings from the first two waves of the 4-H Study of Positive Youth Development. Int J Behav Dev 31(3):263-73.
Ladewig H, Thomas JK. 1987. Assessing the Impact of $4-\mathrm{H}$ on Former Members. The 4-H Alumni Study. The Texas A\&M University System. https://eric. ed.gov/?id=ED282681

Park TD, Dyer JE. 2005. Contribu tions of agricultural education, FFA, and 4-H to student leadership in agricultural colleges. J Agr Education 46(2):83-95. doi:10.5032/jae.2005.02083

Radhakrishna R, Doamekpor P. 2009. Teaching leadership and communication skills and responsibilities: a comparison of 4-H and other youth organizations. J Extension 47(2).

Rayfield J, Murphrey TP, Skaggs C, Shafer J. 2013. Factors that influence student decisions to enroll in a college of agriculture and life sciences. NACTA J 57(1):88-93.
Rusk CP, Summerlot-Early JM, Machtmes KL, et al. 2003. The impact of raising and exhibiting selected 4-H livestock projects on the development of life and project skills. J Agr Education 44(3):1-11.

Schwartz SJ, Phelps E, Lerner JV, et al. 2010. Promotion as prevention: positive youth de velopment as protective against tobacco, alcohol, illicit drug, and sex initiation. Appl Dev Sci 14(4):197-211.

StatPoint Technologies. 2009.

Statgraphics Centurion XVI user manual.

[USCB] US Census Bureau. 2010 U.S. Census Bureau state and county quickfacts: Various California counties. www.census. gov/quickfacts/fact/table/US/ PST045218
Ward CK. 1996. Life skill development related to participation in 4- $\mathrm{H}$ animal science projects. J Extension 34(2)

Wildman M, Torres RM. 2001 Factors identified when selecting a major in agriculture. J Ag Education 42(2):46-55.

ingenbach GJ, Meighan T, Lawrence LD et al. 1999. Associated factors in recruitment and retention of 4- $\mathrm{H}$ members in West Virginia. J Agr Education 40(1):23-9. 